\title{
Hemotoxic Snakebite Presenting with Bilateral Blindness Due to Ischemic Occipital Infarcts
}

\author{
Kodiatte Abraham $\mathrm{A}^{1}$, Livingston John ${ }^{2}$
}

\begin{abstract}
Cerebrovascular complications are rare following a Viperidae snake envenomation, let alone ischemic ones. This catastrophic hemorrhaging cascade is widely known to cause a wide array of manifestations. Its manifestations can range from skin bleeds to fatal intracranial or organ hemorrhages. Our patient had cortical blindness secondary to an ischemic occipital infarct following a hemotoxic snakebite - a seemingly distinct oxymoron. The physician should be mindful of the fact that a hemotoxic snakebite can deceptively bring in ischemic attacks as well. Toxic vasculitis, thrombotic angiopathies, widespread vasospasm and endothelial damage are believed to shoulder a part of the disease process that can bring about tissue ischemia.

Keywords: Cortical blindness, Hemotoxic snakebite, Ischemic infarcts

Key Messages: Hemotoxic snake envenomation can have devastating effects. Apart from dealing with the threat of coagulopathy, the physician must also be alert to the ironical ischemic aftermath that can equally bring in misery. Our patient had one such complication—bilateral cortical blindness resulting from bilateral occipital ischemic infarcts. The physician must be aware that a hemotoxic snakebite can even instigate ischemic dilemmas, i.e. cerebrovascular infarcts, as well.
\end{abstract}

Indian Journal of Critical Care Medicine (2019): 10.5005/jp-journals-10071-23125

\section{INTRODUCTION}

Snakebites and the systemic complications accompanying Senvenomation continues to threaten and impair quality of life through the ruthless effects of its toxins. Hemotoxic snake envenomation is very well known to trigger a devastating sequelae of events ultimately leading to a violent, untimely demise. Its management involves a swift assessment and initiation of antisnake venom (ASV) alongwith furnishing an indispensable supportive line of treatment-a daunting, but rewarding mission, with a precise modus operandi. The timely application of the 20-minute whole blood clotting time (20WBCT) can be used as a trustworthy gauge for treatment especially in a resource-restricted setting. Once the envenomation cascade commences, the morbidity and mortality escalates. Simply put, the clinical syndrome conventionally comprises of 'bleeding organs and organ failures'. It should be recalled that although an oozing, hemorrhaging patient is an exemplar of a hemotoxic snake envenomation, it can result in ischemic infarctions as well. Our patient developed multiple brain infarctions which resulted in a poor sensorium and bilateral blindness, apart from the stereotypical skin bleeding, gastrointestinal bleeding and kidney injury. This condition of cortical blindness subsequent to ischemic infarctions of the bilateral occipital areas following a hemotoxic snake envenomation is a rarity. Table 1 lists the reported causes of blindness following snakebite ${ }^{1-3}$. As such, over a dozen reported cases of ischemic strokes following a hemotoxic snake bite were found in the medical literature ${ }^{4-21}$. Cortical blindness was seen in only 4 cases $^{20-23}$. Apart from the vicious outcomes resulting from coagulopathy, toxic vasculitis, endothelial damage and vasospasm can also lead to significant injury as seen in our affected individual.

\section{Case History}

We present a case of 33-year-old farmer who was brought to the Emergency ward 3 hours after being bitten on his foot by a snake
${ }^{1}$ Department of Medicine, Christian Medical College and Hospital, Ludhiana, Punjab, India

${ }^{2}$ Department of Cardiology, Christian Medical College and Hospital, Ludhiana, Punjab, India

Corresponding Author: Kodiatte Abraham A, Department of Medicine, Christian Medical College and Hospital, Ludhiana, Punjab, India, e-mail: abrahamkodiatte@yahoo.com, Phone: +91-9780280094

How to cite this article: Kodiatte Abraham A, Livingston J. Hemotoxic Snakebite Presenting with Bilateral Blindness Due to Ischemic Occipital Infarcts. Indian J of Crit Care Med 2019;23(2): 99-101.

Source of support: Nil

Conflict of interest: None

Table 1: Reported causes of blindness following snakebite

- Snake venom ophthalmia (acute contact reaction of the ocular surface to venom from the spitting cobra, causing corneal opacities and ulcers or global necrosis)

- Acute angle closure glaucoma following capillary leak syndrome

- Vitreous hemorrhage (following hemotoxic snake envenomation)

- Retinal hemorrhage, infarctions and detachments

- Optic neuritis (Following neurotoxic snake envenomation)

- Postneuritic optic atrophy (following neurotoxic snake envenomation)

- Occipital infarction

while working in his plantation. Two hours following the snakebite, he developed hematuria, bruises over the skin and bleeding from his gums. Since he nor his colleagues were able to identify the species or capture the snake, his clinical syndrome was presumably attributed to a hemotoxic Viperidae snake envenomation. Minutes prior to his arrival to our center, he began speaking irrelevantly. On arrival, he was found to be delirious, both pupils equally reacting bilaterally to light and moving all of his limbs in an erratic manner.

(c) The Author(s). 2019 Open Access This article is distributed under the terms of the Creative Commons Attribution 4.0 International License (http://creativecommons. org/licenses/by/4.0/), which permits unrestricted use, distribution, and non-commercial reproduction in any medium, provided you give appropriate credit to the original author(s) and the source, provide a link to the Creative Commons license, and indicate if changes were made. The Creative Commons Public Domain Dedication waiver (http://creativecommons.org/publicdomain/zero/1.0/) applies to the data made available in this article, unless otherwise stated. 
Table 2: Blood investigations

\begin{tabular}{|c|c|c|c|c|}
\hline \multicolumn{5}{|c|}{ Parameter } \\
\hline & At the time of arrival & $\begin{array}{l}6 \text { hours after infusion of } \\
\text { 1st batch of ASV vials }\end{array}$ & $\begin{array}{l}6 \text { hours after infusion of } \\
2 \text { nd batch of ASV vials }\end{array}$ & $\begin{array}{l}6 \text { hours after infusion } \\
\text { of 3rd batch of ASV vials }\end{array}$ \\
\hline Hemoglobin (g/dL) & 11.4 & 11.0 & 10.9 & 10.7 \\
\hline Total leucocyte count (cells $/ \mathrm{mm}^{3}$ ) & 23,300 & 21,000 & 22,700 & 27,300 \\
\hline Platelet count (cells $/ \mathrm{mm}^{3}$ ) & $1,90,000$ & $1,67,000$ & $1,58,000$ & $1,48,000$ \\
\hline Prothrombin time (INR) & $37.8 / 10.5(3.6)$ & $29.4 / 10.5(2.8)$ & $16.8 / 10.5(1.6)$ & $11.5 / 10.5(1.1)$ \\
\hline Activated partial thromboplastin time & $40.5 / 28$ & $36.5 / 28$ & $29.5 / 28$ & $29.5 / 28$ \\
\hline Blood urea $(\mathrm{mg} / \mathrm{dL})$ & 66 & 52 & 42 & 34 \\
\hline Serum creatinine $(\mathrm{mg} / \mathrm{dL})$ & 1.2 & 1.3 & 1.2 & 1.5 \\
\hline Serum sodium (mEq/L) & 148 & 138 & 134 & 138 \\
\hline Serum potassium (mEq/L) & 3.6 & 4.3 & 4.1 & 3.7 \\
\hline Serum chloride (mEq/L) & 114 & 115 & 110 & 107 \\
\hline Serum creatinine phosphokinase $(\mathrm{mg} / \mathrm{dL})$ & 5950 & 6120 & 5850 & 5340 \\
\hline Fibrinogen (mg/dL) & 403 & 386 & 354 & 412 \\
\hline D-dimer & Negative & Negative & Negative & Negative \\
\hline 20WBCT & Not coagulated & Not coagulated & Not coagulated & Coagulated \\
\hline
\end{tabular}

His heart rate was $104 / \mathrm{min}$, blood pressure $126 / 72 \mathrm{~mm} \mathrm{Hg}$ and a respiratory rate of $22 / \mathrm{min}$. Two distinct fang marks $1.6 \mathrm{~cm}$ apart which were bleeding, minimal surrounding induration and erythema were seen over his left heel. He had multiple ecchymotic patches over his body and had blood oozing from his gums.

With the given clinical diagnosis, a 20WBCT was performed (and expectedly found to be deranged) and 10 vials of polyvalent ASV was given. The ASV was given 3 and a half hours after the snakebite. The protocol for ASV administration, was in accordance with his clinical stability, coagulation parameters and 20WBCT. Additionally, two batches of 10 ASV vials were given, 6 hours after the first batch, 6 hours apart, each preceded by coagulation parameter testing, until it normalised (i.e. a total of 30 polyvalent ASV vials were given). His blood investigations (Table 2) additionally revealed an acute kidney injury and a raised creatinine phosphokinase levels for which a forced alkaline diuresis was initiated.

Twelve hours into his hospital stay, his coagulation parameters normalized and his clinical condition improved excepting his mentation. For this reason, an MRI brain with angiography was performed which revealed multiple non-hemorrhagic infarcts involving his bilateral occipitotemporal and parietal regions, left frontal region and right thalamus with angiography being normal. His sensorium gradually improved in the next 24 hours, was aware and was verbally able to communicate to us regarding his bilateral complete visual deficit. A local ophthalmological, fundus and cranial nerve examination of the eye revealed a normal cornea, lens, vitreous humor, retina and optic disk, nil light perception to light and normal pupillary reflexes. An elaborate search for a local cause of blindness using direct ophthalmoscopy, slit lamp examination and intraocular pressure measurement was performed, ruling out a corneal, lens-related, vitreal, retinal or optic nerve abnormality. With all local causes ruled out, his bilateral blindness was attributed to a breach in the postchiasmatic visual pathway, specifically the geniculocalcarine pathway, as a consequence of his bilateral occipital infarcts. He was discharged from hospital and is on regular follow-up and still continues to have his visual impairment.

\section{Discussion}

Our patient developed hemorrhagic manifestations, rhabdomyolysis and ischemic occipital infarcts causing cortical blindness
Table 3: Mechanisms of ischemic cerebrovascular infarcts

- Disseminated intravascular coagulopathy causing vessel occlusions

- Hypercoagulation due to procoagulants in the venom

- Hyperviscosity caused by hypovolemia and hypotension causing vessel occlusion

- Few components of venom can cause severe vascular spasm, endothelial damage, and increased vascular permeability

- Toxic vasculitis

- Thrombotic microangiopathy

Table 4: Cerebrovascular ischemic manifestations of hemotoxic snakebite

\begin{tabular}{l}
\hline Cerebrovascular ischemic manifestations of hemotoxic snake bite \\
\hline - $\quad$ Brontal temporoparieto-occipital ischemic infarct \\
- Cerebellar, pontine and lacunar ischemic infarct \\
- Cerebral ischemic infarct in the left middle cerebral artery \\
territory \\
- Ischemic infarcts in the territory of the left middle cerebral \\
artery, the right posterior cerebral artery, and both superior \\
- Bilateral posterior circulation ischemic infarct \\
- Bilateral cerebellar and occipital ischemic infarct \\
- Bilateral thalamic ischemic infarct
\end{tabular}

following a probable Viperidae snakebite (with an intact anterior visual pathway) Anton syndrome (visual anosognosia) is a rare complication of cortical blindness with denial of vision loss in patients unable to see $e^{24,25}$. The patient, however, was fully aware of his visual deficits. Although it appears contradictory that a hemotoxic snakebite induces an ischemic infarct, this undeniably demonstrates the versatility of the virulent snake toxin. The noncoagulopathic effects of snake toxin have known to be an adverse consequence through various mechanisms listed in Table 3.

The physician must be alert to the dynamic spectrum of snake toxin induced injury. Table 4 summarises the various cerebrovascular ischemic manifestations of a hemotoxic snake bite reported by various authors $4,8,15-21$.

The patient survived this ordeal because of the swift commencement of treatment but had unfortunately experienced a rare 
manifestation in the process, contributing to a significant number of disease-adjusted life years.

\section{Conclusion}

Hemotoxic snake envenomation can have catastrophic consequences. The patient had cortical blindness resulting from ischemic occipital infarcts following a hemotoxic snakebite-an apparent paradox in itself. The physician must be aware of the noncoagulopathic complications by which hemotoxic snake venom can produce which compounds the course of the syndrome.

\section{References}

1. Mustapha SK, Mubi BM et al. Bilateral blindness following snakebite. Trop Doct. 2010 Apr;40:117-118.

2. Menon V, Tandon R et al. Optic neuritis following snake bite. Indian J Ophthalmol 1997;45:236-237.

3. Sahai $A B$, Sinha R. Bilateral blindness following snake bite. Indian J Ophthalmol 1978;26:16.

4. Narang SK, Paleti $\mathrm{S}$ et al. Acute ischemic infarct in the middle cerebral artery territory following a Russell's viper bite. Neurol India. 2009;57:479-480.

5. Mugundhan K, Thruvarutchelvan K et al. Posterior circulation stroke in a young male following snake bite.J Assoc Physicians India. 2008 Sep;56:713-74.

6. Rathnayaka RMN, Kularatne SA et al. Ischemic brain infarcts and intracranial haemorrhages following Russell's viper (Daboia russelii) bite in Sri Lanka. Toxicon. 2017 Jan;125:70-73.

7. Pothukuchi VK, Kumar A et al. A Rare Case Series of Ischemic Stroke Following Russell's Viper Snake Bite in India.Acta Med Indones. 2017 Oct;49:343-346.

8. Gouda S, Pandit V et al. Posterior circulation ischemic stroke following Russell's viper envenomation. Ann Indian Acad Neurol. 2011 OctDec;14:301-303.

9. Paul G, Paul BS et al. Snake bite and stroke: Our experience of two cases. Indian J Crit Care Med. 2014 Apr;18:257-258.
10. Upadhyaya AC, Murthy GL et al. Snake bite presenting as acute myocardial infarction, ischaemic cerebrovascular accident, acute renal failure and disseminated intravascular coagulopathy. J Assoc Physicians India. 2000;48:1109-1110.

11. Krishna PV, Ahmed S et al. Ischemic stroke consequent to snake bite. J NTR Univ Health Sci. 2017;6:192-193.

12. Jeevagan V, Chang T et al. Acute ischemic stroke following Humpnosed viper envenoming; first authenticated case. Thromb J. 2012;10:21.

13. Kumar RM, Babu RP et al. Multiple infarctions involving cerebral and cerebellar hemispheres following viper bite. J Med Soc. 2015;29:51-53

14. Sahoo LK, Mallick AK et al. A Rare Case of Stroke Due to Multiple Ischemic Infarctions following Russell's Viper Envenomation. Med J DY Patil Vidyapeeth. 2018;11:57-58

15. Rebahi H, Nejmi H, et al. Severe Envenomation by Cerastes cerastes Viper: An Unusual Mechanism of Acute Ischemic Stroke. J Stroke Cerebrovasc Dis. 2014 Jan;23:169-172.

16. Bhatt A, Menon AA, et al. Myocarditis along with acute ischaemic cerebellar, pontine and lacunar infarction following viper bite. BMJ Case Reports. 2013;2013:bcr2013200336.

17. Mosquera A, Idrovo LA et al. Stroke following Bothrops spp. snakebite. Neurology. 2003;60:1577-1580.

18. Ittyachen AM, Jose MB. Thalamic infarction following a Russell's viper bite. Southeast Asian J Trop Med Public Health. 2012 Sep;43:1201-1204.

19. DelBrutto OH, DelBrutto, VJ. Neurological complications of venomous snake bites: a review. Acta Neurol Scand. 2012 Jun;125:363-372.

20. Subasinghe $C J$, Sarathchandra $C$ et al. Bilateral blindness following Russell's viper bite - a rare clinical presentation: a case report. J Med Case Rep. 2014;8:99.

21. Mahale R, Mehta A et al. A Case of Bilateral Occipital Lobe Infarcts Following Indian Tree Viper Bite. J Stroke. 2014 Sep;16:205-207.

22. Chacko A, Andronikou $S$ et al. Hypoxic brain injury and cortical blindness in a victim of a Mozambican spitting cobra bite. S Afr J Surg. 2015;53:67-69.

23. Dhaliwal U. Cortical blindness: An unusual sequela of snake bite. Indian J Ophthalmol. 1999;47:191-192.

24. Galetović D, Karlica D et al. Bilateral cortical blindness-Anton syndrome: case report. Coll Antropol. 2005;229:145-147.

25. Maddula M, Lutton S et al. Anton's syndrome due to cerebrovascular disease: a case report. J Med Case Rep. 2009;3:9028. 